This item was submitted to Loughborough's Research Repository by the author.

Items in Figshare are protected by copyright, with all rights reserved, unless otherwise indicated.

\title{
Teammate influences and relationship quality are associated with eating and exercise psychopathology in athletes
}

PLEASE CITE THE PUBLISHED VERSION

\section{PUBLISHER}

Elsevier

\section{VERSION}

AM (Accepted Manuscript)

\section{PUBLISHER STATEMENT}

This paper was accepted for publication in the journal Appetite and the definitive published version is available at https://doi.org/10.1016/j.appet.2019.104404.

\section{LICENCE}

CC BY-NC-ND 4.0

\section{REPOSITORY RECORD}

Scott, Charlotte, Emma Haycraft, and Carolyn Plateau. 2019. "Teammate Influences and Relationship Quality Are Associated with Eating and Exercise Psychopathology in Athletes". figshare.

https://hdl.handle.net/2134/9604508.v1. 
6 Teammate Influences and Relationship Quality are Associated with Eating and Exercise 7 Psychopathology in Athletes

8

11 School of Sport, Exercise and Health Sciences, Loughborough University, LE11 3TU, UK 12 University, Loughborough, LE11 3TU, UK. E-mail address: C.R.Plateau@1boro.ac.uk. 
22 Teammates have a powerful influence on athletes' eating attitudes / behaviours, but less is known about the relative importance of teammate influence mechanisms. The primary aim of this study was to explore the relationships and predictive associations between teammate influences (e.g., modelling of teammates' disordered eating; supportive teammate friendships) and athletes' eating and exercise attitudes and behaviours. A further aim was to identify the presence of any gender differences. Athletes $(\mathrm{N}=1172$, mean age 24 years, $\mathrm{n}=$ 727 female) completed a survey exploring multiple teammate influences, eating and exercise attitudes and behaviours, and psychological wellbeing (anxiety, depression, self-esteem). Many significant relationships were identified between teammate influences and eating / exercise psychopathology. Stepwise regression analysis revealed that a perceived pressure from teammates to lose weight / change shape and perceptions that teammates engaged in disordered eating practices were the best predictors of higher eating and exercise psychopathology. Supportive teammate friendships was the best predictor of lower eating psychopathology and higher levels of healthy exercise behaviours. Encouragement / discouragement to eat healthily were also significant predictors. Teammate influences explained more variance in exercise than eating psychopathology, and total variance explained by teammates was higher for females compared to males. Teammates may have a positive and negative influence on the eating and exercise attitudes / behaviours of athletes; however, gender differences are apparent. Understanding teammate influences on the eating and exercise practices of athletes is important for the development of team-based interventions to reduce or prevent disordered eating and exercise. Future research should explore these relationships longitudinally, considering the role of moderating factors (e.g., sport type, stage of season). 


\section{Teammate Influences and Relationship Quality are Associated with Eating and Exercise}

\section{Psychopathology in Athletes}

Disordered eating and exercise attitudes and behaviours such as binge eating, exercising to alter weight and shape, and dieting (Sundgot-Borgen \& Torstveit, 2010) have been estimated to occur in 20-45\% of female athletes (e.g., Anderson \& Petrie, 2012; Martinsen, Bratland-Sanda, Eriksson, \& Sundgot-Borgen, 2010; Nichols, Rauh, Barrack, Barkai, \& Pernick, 2007), and 10-19\% of male athletes (Greenleaf, Petrie, Carter, \& Reel, 2009; Martinsen, Bratland-Sanda, Eriksson \& Sundgot-Borgen, 2010; Petrie, Greenleaf, Reel, \& Carter, 2008)

Thompson and Sherman (2011) have suggested that pressures from the sport environment (e.g., from judges, spectators, team weigh ins) may contribute to a body-focused rather than performance-focused outlook and that sport pressures may exacerbate unhealthy relationships with weight, body shape and food, eliciting subsequent disordered eating and compulsive exercise behaviours. In particular, pressures and expectations from teammates and coaches may be instrumental in the development of disordered eating behaviours among athletes, as they may emphasise or endorse leanness and muscularity and overtly or covertly exert pressure to diet (Filaire, Rouveix, Pannafieux, \& Ferrand, 2007).

Petrie and Greenleaf's $(2007,2012)$ sociocultural model of disordered eating in athletes conceptualises the potential contribution of weight, size and appearance pressures from coaches, teammates and the wider sporting environment in the development of eating psychopathology (e.g., dietary restraint, bulimic symptomatology). Indeed sport-specific pressures such as strict weight requirements, revealing team uniforms and judging based on aesthetics have been found to uniquely contribute to athletes' eating psychopathology beyond the generic sociocultural pressures experienced by the wider population (Reel, Petrie, Soohoo, \& Anderson, 2013). In particular, teammates are uniquely positioned to influence 
71 athletes' disordered eating and exercise behaviours given the large amount of time spent in each other's company, with sport friendships found to be particularly strong (Smith, UllrichFrench, Walker, \& Hurley, 2006). Furthermore, evidence suggests that as an athlete matures,

74 sport peers replace parents as the primary source of social influence (Chan, Lonsdale, \& 75 Fung, 2012) and social support (Helsen, Vollebergh, \& Meeus, 2000). A deeper

76 understanding of the mechanisms through which teammates can be influential is therefore 77 vital. However, research exploring the validity of Petrie and Greenleaf's sociocultural model specifically in relation to teammates is limited by the use of single items to investigate the prevalence of a general "teammate pressure" to lose weight / change shape (Petrie, Greenleaf,

Carter \& Reel, 2007; Petrie, Greenleaf, Reel \& Carter, 2009a). This prohibits a deeper understanding of the different social influence mechanisms that may constitute such pressure, how they relate to specific aspects of disordered eating (i.e., restriction, bulimic tendencies) or, indeed, the positive influence teammates may have.

A wide body of empirical and theoretical research has suggested that people primarily influence each other's attitudes and behaviours around food via the following mechanisms: (1) modelling - the imitation of attitudes and behaviours towards food (Cruwys, Bevelander \& Herman, 2015); (2) social facilitation - increasing food intake as a result of eating with others (Herman, 2015); and, (3) social norms - implicit rules around what attitudes and behaviours toward food are socially acceptable (Higgs, 2015). In athletic populations, a recent systematic review revealed that teammates may both positively and negatively impact on athletes' eating attitudes and behaviours via such social influence mechanisms (Scott, Haycraft, \& Plateau, 2019).

With regard to negative teammate influence, evidence suggests that observing and modelling of disordered eating attitudes or pathogenic weight control behaviours among teammates (Greenleaf, Petrie, Reel, \& Carter, 2010; Petrie et al., 2007), may promote the 
development of unhealthy social norms for eating among athlete groups. Indeed, Engel et al. (2003) suggested that athletes may unwittingly encourage disordered eating in team members via the "false consensus effect" (Krueger \& Clement, 1994), whereby athletes are likely to overestimate the frequency of disordered eating attitudes and behaviours among their peers and adopting such behaviours themselves. Additionally, if relationships with teammates are characterised by conflict and distrust, this may facilitate the development of disordered eating behaviours (Shanmugam, Jowett \& Meyer, 2014).

Teammate subcultures can have both a positive and negative impact on athletes' disordered eating. Existing evidence has primarily focused on the aforementioned negative impact, however, it is important to note that teammates can play an important role in the prevention of disordered eating - an area that warrants further research attention. For example, athletes may provide anti-dieting advice and employ effective within-team identification strategies / social norms around the acceptability of seeking professional support / treatment where necessary (Kroshus, Goldman, Kubzansky, \& Austin, 2014; Kroshus, Kubzansky, Goldman, \& Austin, 2015). Teammates have also been found to engage in the promotion of healthy eating. For instance, teammates can have positive influences in relation to food quality (e.g., encouragement to eat fruit and vegetables), quantity (encouragement to eat more), and maintaining healthy routines (e.g., adequately fuelling before a match) (Hausenblas \& Carron, 2000). Furthermore, having teammate relationships characterised by support, warmth and trust has been prospectively related to lower levels of disordered eating behaviours (Shanmugam et al., 2014).

It is likely that susceptibility to sport-related pressures from teammates (e.g., around food intake or dieting) and disordered eating and exercise may vary according to the psychological wellbeing and gender of the athlete. For example, low self-esteem is related to food restriction, drive for thinness and increased risk of compulsive exercise (Brannan, 
121 Petrie, Greenleaf, Reel, \& Carter, 2009; Engel et al., 2003, McNamara \& McCabe, 2012),

122 and high levels of depression and anxiety are more likely to be found in athletes with eating

123 psychopathology (Giel et al., 2016). Furthermore, although not identified with teammates,

124 negative affect (e.g., low self-esteem, high depression and / or anxiety) played a mediating

125 role in the relationship between coach / parent influences and eating psychopathology in

126 athletes (Shanmugam, Jowett, \& Meyer, 2013). Additionally, the internalisation of body

127 ideals (e.g., "thin" or "athletic") is more prevalent in females (Flament et al., 2012) and a risk

128 factor for disordered eating and compulsive exercise in female athletes (Homan, 2010), while

129 physical appearance is more important for teammate acceptance in female athletes compared

130 to males (Jones, 2004; Jones \& Crawford, 2006).

These additional pressures potentially increase female athletes' susceptibility to appearance related teammate influences (e.g., pressure to lose weight). In light of this, when investigating the mechanisms by which teammates may contribute towards and / or protect against the development of eating and exercise psychopathology, it is essential that gender and psychological wellbeing differences are taken into account.

In summary, in order to accurately inform future team-based disordered eating and exercise prevention strategies, it is vital that researchers disentangle different mechanisms of teammate influence and establish the relative importance of various teammate influences (both positive and negative) on athletes' disordered eating and exercise behaviours. Research

140 to date is limited by small and unrepresentative samples (e.g., Berry \& Howe, 2000; Kroshus

141 et al., 2015) and has not accounted for psychological wellbeing / gender differences.

142 Furthermore, investigations have often only tested the relationship between a single

143 mechanism of teammate influence (e.g., modelling, Engel et al., 2003) and a global measure

144 of disordered eating (e.g., global EDEQ scores; Shanmugam et al., 2013) or disordered

145 exercise (e.g., global EDEAS scores; McNamara \& McCabe, 2012), which severely limits the 
understanding of how teammates may differentially impact upon the more discreet constructs

147 that comprise eating/exercise psychopathology (e.g., body dissatisfaction vs drive for

148 thinness or exercise to control weight vs exercise to improve mood).To address these

149 literature gaps, the primary aim of the present study was to comprehensively assess the

150 relationships and predictive associations between multiple teammate influence mechanisms and multiple indices of disordered eating and exercise in a large and representative sample of athletes. A further aim was to identify whether these relationships differed by gender given the aforementioned differences in the prevalence of eating/exercise psychopathology and susceptibility to teammate influence. influences from teammates (e.g., supportive friendships, anti-dieting advice, encouragement of healthily eating) would significantly predict lower levels of eating and exercise psychopathology, whereas negative influences from teammates (e.g., bulimia modelling, perceived pressure to lose weight / change shape, discouragement of healthy eating, conflicting friendships) would significantly predict higher levels of eating and exercise psychopathology. It was predicted these relationships would be more evident for female than male athletes.

\section{Method}

\section{Participants}

The inclusion criteria required participants to be athletes aged 15 years and over

166 competing in any Olympic, International Olympic Committee (IOC) or British Universities

167 and Colleges Sport (BUCS) recognised sport (circa 90 different sports). To be included, participants had to be actively training in a group and / or competing as part of a team in a sport at local, regional, national or international level. Teammates were defined as fellow 
athletes that the participant regularly trains and / or competes with. Currently injured athletes were permitted to take part and were asked to report how long they had been injured for. The present sample comprised 1172 athletes $(n=727$ female; 92\% white ethnicity) with a mean age of 24.04 years $(\mathrm{SD}=9.96)$ and a mean $\mathrm{BMI}$ of $22.66 \mathrm{~kg} / \mathrm{m}^{2}(\mathrm{SD}=3.37$, range 15.60-41.10). Twenty-two percent of the athletes reported currently competing at an elite level (international or national standard), while the remaining 78\% reported currently competing at county, regional, club or university/school level. However, $40 \%$ of the overall sample reported having previously competed at elite level. The athletes represented a range of sports (49\% competed as part of a team), with $61 \%$ engaging in lean sports (e.g., aesthetic, endurance, weight-class) and the remaining 39\% competing in non-lean sports (e.g., ballgame, power, technical). The athletes had been participating in their sport for an average of 6.53 years $(\mathrm{SD}=5.69)$ and trained an average of 8.10 hours $(\mathrm{SD}=5.54)$ per week. At the time of participating, $20 \%$ of athletes were in a pre-season phase, $48 \%$ were in their competitive season and $32 \%$ were in a post-season phase. Five percent of athletes $(n=56)$ reported being currently injured / ill for a mean duration of 7.3 months $(\mathrm{SD}=11.44)$.

\section{Procedure}

Ethical approval was obtained from the Institutional Ethics Approvals (Human Participants) Sub-Committee. Different procedures were employed to recruit adult (aged 18 years and above) and adolescent (aged 15-17 years) athletes. Adults were recruited via adverts about the study which were sent by email to local sport clubs, posted on social media or distributed in person at training sessions / competitions. Adolescents were recruited via key gatekeepers (e.g., PE teachers, coaches, sport club chairpersons) in the local area (East Midlands, UK). After obtaining parental consent, paper versions of the questionnaire were administered to adolescent athletes by their coaches or PE teachers at the beginning of a training session or during a school PE lesson. All participants were required to read the study 
195

196

197

198

199

200

201

202

203

204

205

206

207

208

209

210

211

212

213

214

215

216

217

218

219

information sheet and provide informed consent (adults) or assent (adolescents) prior to completing the survey online $(n=921 ; 78 \%)$ or on paper $(n=255 ; 22 \%)$ between April 2017 and January 2018.

\section{Measures}

The following section provides an overview of the measures used and their reliability in the present study.

Demographics. Participants reported their age, gender, ethnicity, self-reported weight and height and English-speaking status, as well as providing information about their sporting involvement.

\section{Eating and exercise psychopathology.}

Eating Disorder Inventory-2 (EDI-2; Garner, 1991). The EDI-2 was used to assess

disordered eating attitudes and had been widely used with athlete populations (e.g., Plessow

et al., 2018; Ringham et al., 2006). For the present study, only the three subscales comprising the short form of the EDI were used: (1) Drive for Thinness (EDI-DT; 7 items), (2) Body

Dissatisfaction (EDI-BD; 9 items), and (3) Bulimia (EDI-BU; 7 items). Participants respond according to a 6-point Likert scale ranging from "never" to "always". Responses were totalled for each subscale with higher scores indicating higher levels of eating psychopathology. Internal consistency was good for females (EDI-DT; $\alpha=0.85$, EDI-BD; $\alpha$ $=0.88$, EDI-BU; $\alpha=0.80$ ), acceptable for males (EDI-DT; $\alpha=0.74$, EDI-BD; $\alpha=0.79$, EDIBU; $\alpha=0.71$ ) and similar to other athlete populations (e.g., Ringham et al., 2006).

\section{Compulsive Exercise Test - athlete version (CET-A; Plateau et al., 2014). The CET-A} assesses compulsive exercise behaviours. Participants respond to 15 questions via a 6-point Likert scale ranging from "never true" (0) to "always true" (5). The measure comprises three subscales: (1) avoidance of negative affect (CET-A; 6 items), (2) mood improvement (CETMI; 5 items) and (3) weight control (CET-WC; 4 items). Responses were averaged for each 
subscale and higher scores indicate higher levels of compulsive exercise. Internal reliability of the three subscales ranged from $\alpha=0.87-0.91$ for females and $\alpha=0.82-0.92$ for males, which is a slight improvement compared to its use with other athlete populations (Madigan, Stoeber, \& Passfield, 2017). Teammate influence.

Friends Anti-Dieting Scale (FADS; Shroff, 2004).The FADS was used to assess the frequency of receipt of anti-dieting advice. This 5-item scale has been validated for use with athletes (Kroshus et al., 2015). In the current study, the wording of the items was slightly modified to assess 'weight-control behaviours' in addition to dieting. For example, 'How often do your teammates tell you not to diet or engage in weight control behaviours because it's unhealthy?" Participants responded on a 5-point Likert scale from "never" (1) to "very often" (5). Higher total scores indicate a higher frequency of receipt of anti-dieting and antiweight control advice from teammates. Internal consistency in the present sample was $(\alpha=$ 0.74) for females and ( $\alpha=0.66)$ for males, which is on par with other studies (Kroshus et al.,

Nader, 1987). The SSES measures perceived encouragement (e.g., "Complimented me on my healthy eating habits") and discouragement/sabotage (e.g., "Offered me foods I'm trying not to eat") from friends to eat healthily via 10 items and two subscales (encouragement;

239 discouragement). It has been validated in a variety of populations (e.g., Walker, Pullen,

240 Hertzog, Boeckner, \& Hageman, 2006) although it has yet to be validated with athletes. To tailor the SSES to the athlete population, participants were instructed to answer in relation to

242 their teammates and two additional items were added to the scale: "Encouraged me to eat 243 unhealthy foods before or after training" (discouragement subscale) ; "Offered me healthy

244 foods before or after training" (encouragement subscale). A 5-point Likert scale was used 
ranging from "never" (1) to "very often" (5). Higher total scores on each subscale indicated greater levels of encouragement or discouragement to eat healthily from teammates.

247 Bulimic Modelling Scale (BMS; Stice, 1998). The BMS assesses modelling of unhealthy

248 eating behaviours. One item addressed each of the following: (1) dietary restraint, (2)

249 preoccupation with body dimensions, (3) extreme weight control behaviours, (4) binge

250 eating, and (5) vomiting to control weight. For the present study, athletes were instructed to think about their teammates when answering the questions. An additional item was added to address the modelling of nutritional supplement use, and where relevant, items were altered to improve relevance to male athletes. For example, "One or more of my teammates has vomited to lose weight and / or change their shape". A 5-point Likert scale was used ranging from "never" (1) to "very often" (5). Higher mean scores indicated higher levels of modelling behaviours. Internal consistency in the present sample was good for females $(\alpha=0.82)$, acceptable for males ( $\alpha=0.77$; males) and comparable to other studies which have used the original version (Stice, 1998).

Sport Specific Quality of Relationship Inventory (SSQRI; Jowett, 2009). The 12-item SSQRI assesses perceptions of teammate relationship quality. A 4-point Likert scale ranging from "not at all" (1) to "very much" (4) was used to assess social support (SSQRI-S; 6 items) and interpersonal conflict (SSQRI-C; 6 items). Scores were averaged for each subscale, with higher scores reflecting higher levels of support and conflict in the relationship. Internal consistency was good for both subscales (females: SSQRI-S; $\alpha=0.87$, SSQRI-C $\alpha=0.87$; males: SSQRI-S; $\alpha=0.85$, SSQRI-C $\alpha=0.85$ ) and comparable to other athlete samples

266 (Shanmugam, 2011).

267 Perceived Sociocultural Pressures Scale (PSPS; Stice \& Bearman, 2001). The PSPS assesses perceived pressure to lose weight / change shape and has been previously validated in athlete samples (e.g., Galli, Petrie, Reel, Chatterton, \& Baghurst, 2014). Three items specifically 
assess pressure from teammates and participants responded using a 5-point Likert scale

271

272

273

ranging from "none" (1) to "a lot" (5). The items were as follows: (1) "My teammates tease me about my weight or body shape", (2) "I've noticed a strong message from my teammates to have a thin body", and (3) "I've felt pressure from my teammates to lose weight". A higher mean score reflects greater perceived pressure to lose weight / change shape from teammates. The internal consistency for the PSPS-Teammate was $\alpha=0.63$ for females and $\alpha=0.65$ for males which is slightly lower in comparison to other studies using similar samples (Galli et al., 2014).

\section{Psychological wellbeing.}

Rosenberg's Self Esteem Scale (RSES; Rosenberg, 1965). The 10-item RSES measures global self-esteem and has previously been successfully employed with athlete populations (e.g., Holm-Denoma, Scaringi, Gordon, Van Orden, \& Joiner, 2009). Participants respond via a 4point Likert scale ranging from "strongly agree" (1) to "strongly disagree" (4). A total score was calculated, with higher scores reflecting greater self-esteem. Internal reliability for the RSES was good for males $(\alpha=0.89)$, excellent for females $(\alpha=0.91)$ and in line with previous athlete research (e.g., Shanmugam, 2011).

Hospital Anxiety and Depression Scale (HADS; Zigmond \& Snaith, 1983). The HADS measures anxiety ( 7 items) and depression ( 7 items) symptoms and has been widely used with athletes (e.g., Goodwin, Haycraft, Willis, \& Meyer, 2011; Weber et al., 2018). Participants are asked to indicate the degree to which the statements are reflective of how they have been feeling and responses are made on a 4-point scale (e.g., "not at all" (0) to "most of the time" (3)). Total scores were calculated for each subscale to provide a measure of anxiety and depression (mild case $=8-10$, moderate case $=11-14$, severe case $=15+$; Stern, 2014). For the present study, internal consistency was good / acceptable for anxiety 
294 (females; $\alpha=0.84$, males: $\alpha=0.79$ ) and acceptable / low for depression (females: $\alpha=0.77$, 295 males: $\alpha=0.68)$.

\section{Data Analysis}

All analyses were conducted using IBM SPSS 24.0. Shapiro-Wilk tests indicated that very few of the variables were normally distributed, therefore, non-parametric tests were employed where appropriate. Confirmatory Factor Analysis confirmed that the two items added to the SSES loaded onto the subscales as expected, and the internal consistency of the subscales was found to be good for the Encouragement subscale (females: $\alpha=0.83$, males: $\alpha$ $=0.82$ ) and acceptable for the Discouragement subscale (females: $\alpha=0.77$, males: $\alpha=0.74$ ). Mann Whitney U tests were conducted to explore gender differences on study variables and to inform the correlations and stepwise regressions.

To address the first part of the aim, Spearman's two-tailed correlations were psychopathology to assess whether significant relationships existed between these variables. Two-tailed Spearman's rho correlations were also run to examine whether covariates (selfesteem, anxiety, depression, age and BMI) significantly correlated with eating and exercise variables. Where significant associations were identified, these were controlled for in the first step of the subsequent regression analyses, given that age, BMI and psychological wellbeing have been widely associated with elevated eating psychopathology (e.g., Neumark-Sztainer,

313 Story, Hannan, Perry, \& Irving, 2002; Shanmugam, Jowett, \& Meyer, 2012). To address the

314 second part of the aim, hierarchical regressions were conducted separately by gender to identify which teammate influences were predicted eating and exercise psychopathology,

316 after accounting for covariates. In addition to age, BMI and psychological wellbeing, sport

317 type (dummy coded; lean vs non-lean) and competitive level (dummy coded: elite (national 318 and international) vs non-elite (school, club, university, regional)) were entered into the first 
step of all regressions, given evidence to suggest these variables are associated with differential levels of eating/exercise psychopathology (e.g., Rosendahl, Bormann, Aschenbrenner, \& Strauss, 2009). To reduce the risk of a Type 1 error, a $p$ value of $p<0.01$ was employed for all analyses.

\section{Results}

\section{Descriptive statistics}

Descriptive statistics and tests of difference between male and female participants are presented in Table 1. Eating and exercise psychopathology scores for the current sample were broadly comparable to existing research conducted with athletes (e.g., Hausenblas \& McNally, 2004). In terms of psychological wellbeing, mean scores on HADS-Depression (whole sample) and HADS-Anxiety (male athletes only) indicated low levels of depression and anxiety within the sample, which is comparable with other athlete populations (e.g., Halfdanardottir, 2016; Weber et al., 2018). However, for female athletes, mean HADSAnxiety scores indicated mild anxiety symptoms within the sample (Stern, 2014), which is higher than found previously with athletes (e.g., Halfdanardottir, 2016; Weber et al., 2018). Significant gender differences with small effect sizes (medium for EDI-body dissatisfaction) were identified for all eating and exercise psychopathology and psychological variables aside from HADS-Depression. Gender differences with small effect sizes were also apparent for Encouragement of Healthy Eating (Social Support for Eating Survey-

Encouragement), Bulimia Modelling (Bulimia Modelling Scale) and Supportive Friendships (Sport-Specific Quality of Relationship Inventory-Support), where females scored higher than males. 
342 Table 1. Participant characteristics and tests of difference between males and females $(\mathrm{N}=1172)$.

\begin{tabular}{|c|c|c|c|c|c|c|}
\hline \multirow[t]{2}{*}{ Measure } & \multirow{2}{*}{$\begin{array}{l}\text { Total } \\
(\mathrm{N}=1172) \\
\text { Mean (SD) }\end{array}$} & \multirow{2}{*}{$\begin{array}{l}\text { Males } \\
(n=445) \\
\text { Mean (SD) }\end{array}$} & \multirow{2}{*}{$\begin{array}{l}\text { Females } \\
(n=727) \\
\text { Mean (SD) }\end{array}$} & \multicolumn{3}{|c|}{ Mann-Whitney U } \\
\hline & & & & $\mathrm{Z}$ & $\mathrm{p}$ & $\begin{array}{l}\text { Effect } \\
\text { size (r) }\end{array}$ \\
\hline Age (years) & $24.04(10.09)$ & $23.07(9.70)$ & $24.62(10.10)$ & 4.21 & 0.01 & 0.12 \\
\hline BMI & $22.66(3.37)$ & $22.98(3.47)$ & $22.46(3.28)$ & 2.94 & 0.01 & 0.09 \\
\hline $\begin{array}{l}\text { Eating Disorder Inventory- } \\
\text { Drive for Thinness }\end{array}$ & $3.06(4.17)$ & $1.92(3.06)$ & $3.76(4.60)$ & 7.60 & $<0.001$ & 0.22 \\
\hline $\begin{array}{l}\text { Eating Disorder Inventory- } \\
\text { Bulimia }\end{array}$ & $2.45(3.60)$ & $1.53(2.74)$ & $3.01(3.94)$ & 8.44 & $<0.001$ & 0.25 \\
\hline $\begin{array}{l}\text { Eating Disorder Inventory- } \\
\text { Body Dissatisfaction }\end{array}$ & $7.64(6.47)$ & $5.13(4.96)$ & $9.16(6.78)$ & 10.45 & $<0.001$ & 0.30 \\
\hline $\begin{array}{l}\text { Compulsive Exercise Test- } \\
\text { Avoidance of Negative Affect }\end{array}$ & $2.38(1.31)$ & $2.18(1.31)$ & $2.49(1.29)$ & 3.66 & $<0.001$ & 0.11 \\
\hline $\begin{array}{l}\text { Compulsive Exercise Test- } \\
\text { Mood Improvement }\end{array}$ & $3.78(1.20)$ & $3.57(1.31)$ & $3.90(1.10)$ & 3.89 & $<0.001$ & 0.11 \\
\hline $\begin{array}{l}\text { Compulsive Exercise Test- } \\
\text { Weight Control }\end{array}$ & $2.03(1.30)$ & $1.71(1.23)$ & $2.23(1.30)$ & 6.70 & $<0.001$ & 0.20 \\
\hline Friends Anti-Dieting Advice Scale & $9.19(3.45)$ & $8.88(3.14)$ & $9.39(3.63)$ & 1.87 & 0.06 & 0.06 \\
\hline $\begin{array}{l}\text { Social Support for Eating Survey- } \\
\text { Encouragement }\end{array}$ & $12.20(4.75)$ & $12.01(4.58)$ & $12.33(4.84)$ & 4.52 & $<0.001$ & 0.13 \\
\hline $\begin{array}{l}\text { Social Support for Eating Survey- } \\
\text { Discouragement }\end{array}$ & $11.05(3.85)$ & $10.44(3.62)$ & $11.43(3.95)$ & 0.82 & 0.28 & 0.02 \\
\hline Bulimia Modelling Scale & $2.16(0.77)$ & $2.03(0.72)$ & $2.23(0.79)$ & 4.17 & $<0.001$ & 0.12 \\
\hline $\begin{array}{l}\text { Sport-Specific Quality of Relationship } \\
\text { Inventory (SSQRI) - Support }\end{array}$ & $2.91(0.68)$ & $2.80(0.66)$ & $2.97(0.69)$ & 4.19 & $<0.001$ & 0.12 \\
\hline $\begin{array}{l}\text { Sport-Specific Quality of Relationship } \\
\text { Inventory (SSQRI) - Conflict }\end{array}$ & $1.46(0.52)$ & $1.47(0.52)$ & $1.45(0.52)$ & 0.84 & 0.67 & 0.02 \\
\hline $\begin{array}{l}\text { Perceived Sociocultural Pressure Scale- } \\
\text { Teammates }\end{array}$ & $1.34(0.55)$ & $1.32(0.55)$ & $1.35(0.55)$ & 0.30 & 0.48 & 0.01 \\
\hline Rosenberg Self-Esteem Scale & $29.90(6.02)$ & $31.26(5.75)$ & $29.10(6.02)$ & 6.23 & $<0.001$ & 0.18 \\
\hline $\begin{array}{l}\text { Hospital Anxiety and Depression Scale- } \\
\text { Anxiety }\end{array}$ & $8.22(4.14)$ & $7.14(3.80$ & $8.89(4.21)$ & 6.94 & $<0.001$ & 0.20 \\
\hline $\begin{array}{l}\text { Hospital Anxiety and Depression Scale- } \\
\text { Depression }\end{array}$ & $3.78(3.05)$ & $3.62(2.82)$ & $3.85(3.13)$ & 0.75 & 0.21 & 0.02 \\
\hline
\end{tabular}



Two-tailed Spearman's correlations were conducted separately for males and females

345 to explore relationships between demographic variables, teammate influences and

346 psychological wellbeing with eating and exercise psychopathology variables (see Tables 2

347 and 3). Inter-correlations between all variables employed in this study are presented in

348 Supplementary Tables 1 and 2.

349 Females (Table 2). Most associations identified between teammate influences and

350 eating / exercise psychopathology were small. Anti-dieting/anti-weight control advice

351 (Friends Anti-Dieting Advice Scale) and Encouragement of Healthy Eating positively

352 correlated with all eating / exercise variables aside from EDI-Body Dissatisfaction and CET-

353 Mood Improvement. Discouragement of Healthy Eating (Social Support for Eating Survey -

354 Discouragement) and Bulimia Modelling positively correlated with all eating and exercise 355 variables. Conflicting Friendships (Sport-Specific Quality of Relationships Inventory -

356 Conflict) and Teammate Pressure (Perceived Sociocultural Pressure Scale - Teammates)

357 positively correlated with all eating and exercise variables aside from CET-Mood

358 Improvement. Supportive Friendships negatively correlated with EDI-Drive for Thinness,

359 EDI-Body Dissatisfaction and CET-Weight Control, and positively correlated with CET360 Mood Improvement. 
Table 2. Spearman's correlations between teammate influences, psychological wellbeing and eating and exercise variables for females $(n=727)$

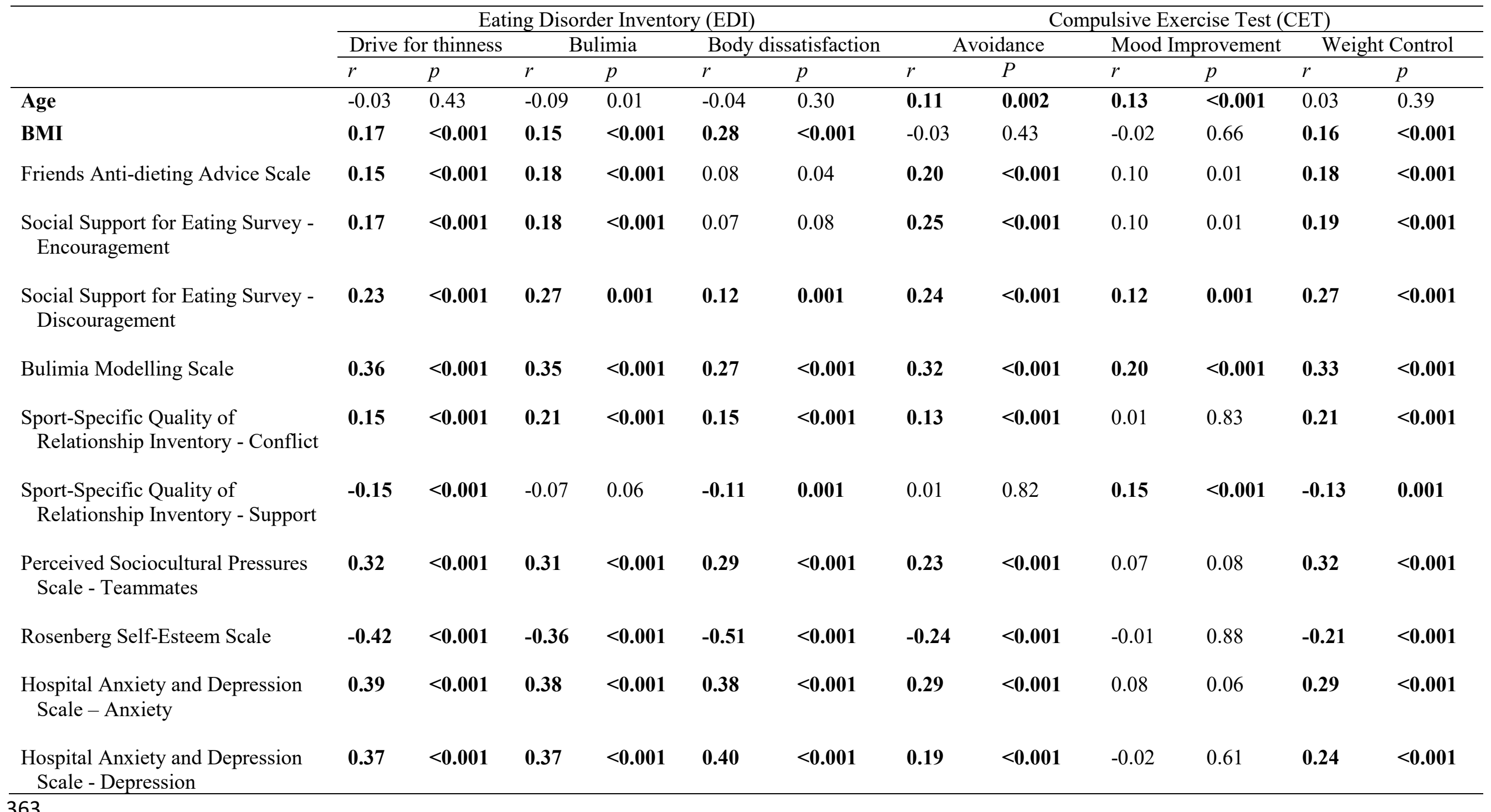


Males (Table 3). Most associations identified between teammate influences and eating / exercise psychopathology were small. Anti-dieting/anti-weight control advice

366 positively correlated with all eating and exercise variables aside from EDI-Body

367 Dissatisfaction and CET-Weight Control. Encouragement of Healthy Eating and Bulimia

368 Modelling positively correlated with all eating and exercise variables aside from EDI-Body

369 Dissatisfaction. Conflicting Friendships positively correlated with EDI-Body Dissatisfaction,

370 while Supportive Friendships negatively correlated with EDI-Body Dissatisfaction and

371 positively correlated with CET-Mood Improvement. Teammate Pressure positively correlated

372 with all eating and exercise variables, while no significant relationships were identified for

373 Discouragement of Healthy Eating. 
Table 3. Spearman's correlations between teammate influences, psychological wellbeing and eating and exercise variables for males $(n=445)$

\begin{tabular}{|c|c|c|c|c|c|c|c|c|c|c|c|c|}
\hline & \multicolumn{6}{|c|}{ Eating Disorder Inventory (EDI) } & \multicolumn{6}{|c|}{ Compulsive Exercise Test (CET) } \\
\hline & \multicolumn{2}{|c|}{ Drive for Thinness } & \multicolumn{2}{|c|}{ Bulimia } & \multicolumn{2}{|c|}{ Body Dissatisfaction } & \multicolumn{2}{|c|}{ Avoidance } & \multicolumn{2}{|c|}{ Mood Improvement } & \multicolumn{2}{|c|}{ Weight Control } \\
\hline & $r$ & $p$ & $r$ & $p$ & $r$ & $p$ & $r$ & $P$ & $r$ & $p$ & $r$ & $p$ \\
\hline Age & -0.003 & 0.95 & 0.06 & 0.20 & 0.02 & 0.67 & 0.28 & $<0.001$ & 0.27 & $<0.001$ & 0.12 & 0.01 \\
\hline BMI & 0.21 & $<\mathbf{0 . 0 0 1}$ & 0.09 & 0.06 & 0.21 & $<\mathbf{0 . 0 0 1}$ & 0.13 & 0.01 & 0.12 & $<\mathbf{0 . 0 1}$ & 0.31 & $<\mathbf{0 . 0 0 1}$ \\
\hline Friends Anti-dieting Advice Scale & 0.14 & 0.001 & 0.15 & 0.001 & 0.07 & 0.16 & 0.22 & $<0.001$ & 0.15 & 0.001 & 0.13 & 0.01 \\
\hline $\begin{array}{l}\text { Social Support for Eating Survey - } \\
\text { Discouragement }\end{array}$ & 0.08 & 0.08 & 0.12 & 0.01 & -0.01 & 0.91 & 0.13 & 0.01 & 0.05 & 0.28 & 0.13 & 0.01 \\
\hline Bulimia Modelling Scale & 0.24 & $<0.001$ & 0.26 & $<0.001$ & 0.11 & 0.02 & 0.35 & $<0.001$ & 0.20 & $<0.001$ & 0.26 & $<0.001$ \\
\hline $\begin{array}{l}\text { Sport-Specific Quality of } \\
\text { Relationship Inventory - Conflict }\end{array}$ & 0.06 & 0.22 & 0.11 & 0.03 & 0.15 & 0.001 & 0.07 & 0.13 & -0.13 & 0.01 & 0.12 & 0.02 \\
\hline $\begin{array}{l}\text { Sport-Specific Quality of } \\
\text { Relationship Inventory - Support }\end{array}$ & -0.05 & 0.27 & -0.01 & 0.84 & -0.25 & $<0.001$ & 0.06 & 0.24 & 0.21 & $<0.001$ & 0.02 & 0.67 \\
\hline $\begin{array}{l}\text { Perceived Sociocultural Pressures } \\
\text { Scale - Teammates }\end{array}$ & 0.28 & $<0.001$ & 0.23 & $<0.001$ & 0.23 & $<0.001$ & 0.28 & $<0.001$ & 0.15 & 0.001 & 0.24 & $<0.001$ \\
\hline Rosenberg Self-Esteem Scale & -0.26 & $<0.001$ & -0.21 & $<0.001$ & -0.41 & $<0.001$ & -0.17 & $<0.001$ & 0.04 & 0.44 & -0.25 & $<0.001$ \\
\hline $\begin{array}{l}\text { Hospital Anxiety and Depression } \\
\text { Scale - Anxiety }\end{array}$ & 0.28 & $<0.001$ & 0.26 & $<0.001$ & 0.29 & $<0.001$ & 0.30 & $<0.001$ & 0.10 & 0.04 & 0.32 & $<0.001$ \\
\hline $\begin{array}{l}\text { Hospital Anxiety and Depression } \\
\text { Scale - Depression }\end{array}$ & 0.30 & $<0.001$ & 0.21 & $<0.001$ & 0.29 & $<0.001$ & 0.05 & 0.27 & -0.13 & 0.01 & 0.19 & $<0.001$ \\
\hline
\end{tabular}


Next, hierarchical regressions were conducted (separately by gender) to determine

379 which teammate influences predicted eating and exercise psychopathology. Covariates (i.e. age, BMI, self-esteem, anxiety and depression) which were significantly correlated with the eating and exercise psychopathology variables were controlled for and entered at the first step of the regression. Sport type and competitive level were also entered into the first step.

383 Teammate influences which were significantly correlated with eating and exercise variables were entered into the second step (see Tables 4-7).

Females. The regression models to assess the predictive role of covariates and teammate influences on eating and exercise variables were significant for all three EDI subscales (Table 4). Covariates explained 26\% (EDI-Drive for thinness), 21\% (EDI-Bulimia) and 36\% (EDI-Body Dissatisfaction) of the total variance. Teammate influences explained an additional 8\% (EDI-Drive for Thinness), 7\% (EDI-Bulimia) and 4\% (EDI-Body

Dissatisfaction, Teammate Pressure made the largest contribution, followed by Bulimia Modelling for EDI-Drive for Thinness. Bulimia Modelling made the largest contribution to

393 EDI-Bulimia followed by Teammate Pressure. The regression models were also significant for all CET subscales (Table 5), with covariates explaining 12\% (CET-Avoidance) and 13\% (CET-Weight Control) of the total variance. Teammate influence variables explained $8 \%$ of the total variance in CET-Mood 397 Improvement and an additional $7 \%$ and $10 \%$ of the variance explained for CET-Avoidance 398 and CET-Weight Control, respectively. Bulimia Modelling made the largest contribution to 399 CET-Avoidance followed by Discouragement of Healthy Eating, Supportive Friendships made the largest contribution to CET-Mood Improvement followed by Bulimia Modelling, and Bulimia Modelling made the largest contribution to CET-Weight Control followed by 
402 Discouragement of Healthy Eating and Teammate Pressure.

403 
404 Table 4. Hierarchical regression analysis predicting disordered eating scores from covariates and teammate influences for females $(n=727)$

$$
\text { Predictor }
$$

Step 1

BMI

Sport type

Competitive level

Self-Esteem

Anxiety

Depression

\section{Step 2}

BMI

Sport type

Competitive level

Self-Esteem

Anxiety

Depression

Anti-dieting Advice

Encouragement of

Healthy Eating

Discouragement of

Healthy Eating

Bulimia Modelling

Supportive Friendships

Conflicting Friendships

Teammate Pressure

$0.15 * *$
$-0.18 * *$
$0.18 * *$
$0.25 * *$

$-0.16^{* *}$

$0.23 * *$ Bulimia

Adj $R^{2} \quad$ F change

$\beta$

$0.20 * *$

$\begin{array}{ll}\text { Adj } \mathrm{R}^{2} & \text { F change } \\ 0.21 & 33.16^{* *}\end{array}$

$\beta$

Body Dissatisfaction

$0.26^{* *}$ Adj $R^{2}$

0.36 F change

$68.82 * *$

$0.34 \quad 12.26^{* *}$

$0.13 * *$

$0.16^{* *}$

0.28

$0.07 * *$

$-0.44 * *$

(1)
$-0.24 * *$
$-0.12 * *$
$-0.35 * *$

$0.16^{* *}$

$0.20 * *$

$0.17 * *$

(2)

$0.24^{* *}$
$0.08^{*}$

$0.24^{* *}$
$0.08^{*}$

$405 \quad * \mathrm{p}<0.01, * * \mathrm{p}<0.001$

406 Note. Teammate influences highlighted. Only significant predictors at $\mathrm{p}<0.01$ reported. 
411 Table 5. Hierarchical regression analysis predicting compulsive exercise scores from covariates and teammate influences for females $(n=727)$

$$
\text { Predictor }
$$

Step 1

Age

BMI

Sport type

Competitive level

Self-Esteem

Anxiety

Depression

Step 2
Age
BMI
Sport type
Competitive level
Self-Esteem

Anxiety

Depression

Anti-dieting Advice

Encouragement of

Healthy Eating

Discouragement of

Healthy Eating

Bulimia Modelling

Supportive Friendships

Conflicting Friendships

Teammate Pressure

$$
\text { Avoidance }
$$
$\beta$

Adj $\mathrm{R}^{2} \quad$ F change
Mood Improvement

$\begin{array}{ll}\text { Adj } \mathrm{R}^{2} & \text { F change } \\ 0.12 & 17.48^{* *}\end{array}$
$\beta$
$-0.12 *$

$0.12 *$

$0.23 * *$

$\begin{array}{ll}\text { Adj } \mathrm{R}^{2} & \text { F change } \\ 0.01 & 3.57\end{array}$

Weight Control

0.13

F change

$0.11 *$

$-0.19 * *$

$0.17 *$

$0.19 \quad 11.55^{* *}$

$0.10 *$

0.08

$18.17 * *$

0.23

$14.87 * *$

$412 * \mathrm{p}<0.01, * * \mathrm{p}<0.001$,

$0.12 *$

$0.14 *$

$0.14 *$

$0.15 * *$

$0.16 * *$

$0.17 * *$

$0.20 * *$

413 Note. Teammate influences highlighted. Only significant predictors at $\mathrm{p}<0.01$ reported.

$0.13 *$ 
Males. The regression models were significant for all EDI subscales (Table 6), with

418 covariates explaining 16\% (EDI-Drive for Thinness), 13\% (EDI-Bulimia) and 26\% (EDI-

419 Body Dissatisfaction) of the total variance. Teammate influences explained an additional 5\%

420 (EDI-Drive for Thinness), 4\% (EDI-Bulimia) and 4\% (EDI-Body Dissatisfaction) of the total

421 variance. Teammate Pressure and Bulimia Modelling made the largest contributions to EDI-

422 Drive for Thinness and EDI-Bulimia, respectively. Supportive Friendships and Teammate

423 Pressure made the largest contributions to EDI-Body Dissatisfaction.

424 The regression models were also significant for all CET subscales (Table 7), with

425 covariates explaining 21\% (CET-Avoidance), 7\% (CET-Mood Improvement) and 15\%

426 (CET-Weight Control) of the total variance. Teammate influences accounted for an

427 additional 8\% (CET-Avoidance), 5\% (CET-Mood Improvement) and 5\% (CET-Weight

428 Control) of the variance. For CET-Avoidance, Bulimia Modelling made the largest

429 contribution to the total variance followed by Teammate Pressure and Encouragement of

430 Healthy Eating. For CET-Mood Improvement, Supportive Friendships made the largest

431 contribution. For CET-Weight Control, Teammate Pressure made the largest contribution. 
432 Table 6. Hierarchical regression analysis predicting disordered eating scores from covariates and teammate influences for males $(n=445)$

$$
\text { Predictor }
$$

$$
\begin{aligned}
& \text { Step 1 } \\
& \text { BMI }
\end{aligned}
$$

Sport type

Competitive level

Self-Esteem

Anxiety

Depression

\section{Step 2}

BMI

Sport type

Competitive level

Self-Esteem

Anxiety

Depression

Anti-dieting Advice

Encouragement of

Healthy Eating

Discouragement of

Healthy Eating

Bulimia Modelling

Supportive Friendships Conflicting Friendships

Teammate Pressure

Drive for Thinness

Adj R
0.16

$$
\text { Bulimia }
$$
$\beta$ $0.20 * *$ F change

Adj R ${ }^{2}$
0.13

$-0.15^{*}$

$0.15^{*}$

$-0.25^{* *}$

$0.21 * *$

$0.17 \quad 7.72 * *$

$0.16^{* *}$

0.21

$9.0 * *$

$7.72 *$

$0.25^{* *}$

0.30

$8.58^{* *}$

$433 * \mathrm{p}<0.01, * * \mathrm{p}<0.001$

434 Note. Teammate influences highlighted. Only significant predictors at $\mathrm{p}<0.01$ reported. 
437 Table 7. Hierarchical regression analysis predicting compulsive exercise scores from covariates and teammate influences for males $(n=445)$

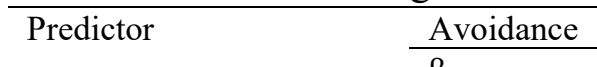

\begin{tabular}{|c|c|}
\hline \multicolumn{2}{|l|}{ Predictor } \\
\hline Step 1 & \\
\hline Age & \\
\hline BMI & \\
\hline Sport type & -0.23 \\
\hline Competitive level & \\
\hline Self-Esteem & \\
\hline Anxiety & $0.43^{*}$ \\
\hline Depression & -0.17 \\
\hline
\end{tabular}

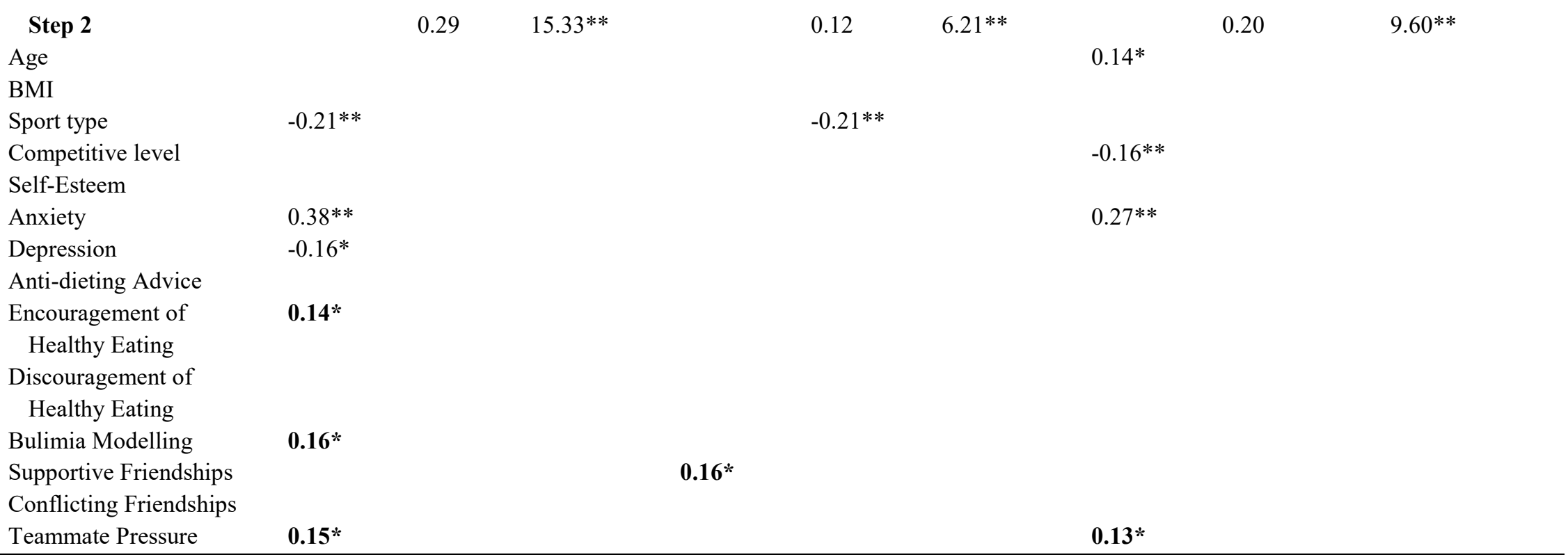

$438 * \mathrm{p}<0.01, * * \mathrm{p}<0.001$

439 Note. Teammate influences highlighted. Only significant predictors at $\mathrm{p}<0.01$ reported. 


\section{Discussion}

The primary aim of this study was to explore the relationships and predictive

444

445

446

associations between a variety of teammate influences and eating and exercise attitudes and behaviours of athletes from a wide range of sports and competitive levels. A further aim was to identify the presence of any gender differences. Significant, small relationships were identified between many of the teammate influence mechanisms and indices of eating / exercise psychopathology. After accounting for indices of psychological wellbeing (selfesteem, anxiety and depression), having supportive teammate friendships was the best (i.e., statistically strongest) predictor of lower eating psychopathology (lower levels of body dissatisfaction) and higher levels of healthy exercise behaviours (i.e., exercising to improve mood), whereas modelling of teammates' disordered eating behaviours and perceived pressure from teammates to lose weight / change shape were the best predictors of higher disordered eating and compulsive exercise levels. Overall, influences from teammates explained more of the additional variance in disordered exercise than disordered eating attitudes and behaviours. Furthermore, teammate influences explained more variance in eating and exercise psychopathology for female athletes. These key findings confirm our hypotheses, provide support for Petrie and Greenleaf's (2012) sociocultural model of disordered eating, and extend prior literature which has yet to consider the relative importance of various teammate influence mechanisms on eating and exercise attitudes and behaviours.

Perceiving pressure from teammates to lose weight / change shape (e.g., add muscle), in addition to perceiving that teammates engaged in disordered eating attitudes and behaviours (e.g., restriction or binging, preoccupation with body dimensions and vomiting to control weight) were the strongest mechanisms of influence associated with elevated disordered eating and exercise behaviours. This aligns with previous literature which has 
467 identified the negative role of perceived teammate pressure to lose weight/change shape (T.

468 A. Petrie et al., 2007; T. A. Petrie, Greenleaf, Reel, \& Carter, 2009b) and modelling of

469 teammates' disordered eating (Engel et al., 2003) on athletes' own disordered eating attitudes

470 and behaviors. However, our findings build on existing literature by demonstrating that

471 perceived teammate pressure to lose weight/change shape and modelling of teammates'

472 disordered eating appear to be more important than other negative teammate influence

473 mechanisms (e.g., having teammate friendships characterised by conflict/distrust or

474 discouragement/sabotage from teammates to eat healthily) in the explanation of elevated

475 levels of disordered eating and exercise. Pervasive social norms and within team

476 "subcultures" (Thompson \& Sherman, 2011) of acceptance around disordered eating and

477 exercise behaviours may explain the strong relationship between an athlete's self-reported

478 behaviour and parallel perceptions of their teammate's behaviours. Athletes are also often

479 acutely aware of their teammates' weight if mandatory team weigh-ins occur (Galli, Petrie, \&

480 Chatterton, 2017), teammate lifting is required (e.g., cheerleading, figure skating, rugby), or

481 where the attire means that the body is clearly visible (e.g., volleyball, swimming). In these

482 contexts, weight and body shape comparisons are easily facilitated (Voelker, Petrie, Reel, \&

483 Gould, 2018) and pressure from teammates may manifest through critical comments about

484 weight / shape (e.g., Muscat \& Long, 2008), subsequently contributing to the disordered

485 eating and exercise attitudes / behaviours identified in the present study.

$486 \quad$ For females, eating and exercise psychopathology were more strongly associated with

487 indices of negative teammate influences than for males. While this finding aligns with

488 existing (descriptive) research which has found that females report receiving more negative

489 teammate influences with regards to their eating behaviours than males (Hausenblas \&

490 Carron, 2000), the findings from the present study extend research by documenting how

491 teammates are being influential (i.e., via teammate pressure to lose weight/change shape) and 
492 the relative strength of teammate influence on female athletes' eating and exercise

493 psychopathology. Disordered eating prevention efforts that take account of the specific

494 dynamics of female peer groups (e.g., "girl talk" support groups, McVey, Lieberman,

495 Voorberg, Wardrope, \& Blackmore, 2003) may be a useful approach to reduce levels of

496 disordered eating and exercise in this already at-risk population (Torstveit, Rosenvinge, \&

497 Sundgot-Borgen, 2008).

498 With regard to positive teammate influences, this study identified that supportive

499 teammate relationships (characterised by warmth, compassion and an absence of conflict)

500 was the only mechanism of influence significantly associated with lower levels of eating

501 psychopathology (body dissatisfaction) and higher levels of healthy exercise behaviours (e.g.,

502 exercise to improve mood). This finding is in line with studies that have explored these

503 relationships longitudinally (e.g., Shanmugam et al., 2014) and have found high quality

504 teammate friendships to be protective against disordered eating attitudes (e.g., Scoffier,

505 Maïano, \& d'Arripe-Longueville, 2010). Importantly, the current study extends existing

506 research by indicating that having supportive teammate friendships is more strongly related

507 to healthier eating and exercise attitudes and behaviours than receiving anti-dieting/antiweight control advice from teammates which (although not identified as a predictor in the present study) has been previously linked with lower eating psychopathology (Kroshus et al.,

$5102014,2015)$. This finding highlights an important target for future intervention programmes

511 aiming to prevent unhealthy eating and exercise behaviours in athletes.

A finding novel to this study was the association between encouragement from teammates to eat healthily and avoid unhealthy foods and increased levels of compulsive

514 exercise. This is contrary to a wide body of literature from the general population

515 demonstrating associations between encouragement to eat and / or exercise healthily and

516 subsequent healthy eating / exercise behaviours (Bauer, Nelson, Boutelle, \& Neumark- 
517 Sztainer, 2008; Larson et al., 2008). Given the cross-sectional nature of our study, it is not

518 possible to unpack the temporal precedence. It is plausible to suggest that a focus on healthy

519 eating behaviours within a team might serve to promote excessive weight pre-occupation and

520 disordered avoidance of unhealthy foods (Dixey, 1996). Indeed, compensatory practices such

521 as exercise are widely accepted as the appropriate behavioural response to the consumption

522 of unhealthy food (Lenne et al., 2017). Given their often rigid diet and exercise habits (Bonci

523 et al., 2008), athletes may have distorted notions of what it is to be healthy. For example, by

524 having strict adherence to, and obsessive routines around, consuming particular

525 macronutrients (e.g., lean protein) (Segura-Garcia et al., 2012). Input from teammates

526 encouraging healthy eating may promote such obsessive and rigid practices and potential

527 engagement in compulsive exercise, as demonstrated in this study. Further longitudinal work

528 is needed to unpack this finding, but it could be important to reduce the focus on 'healthy'

529 eating practices in teams in order to reduce disordered eating / exercise practices.

530 Uniquely, this study found that teammate influences accounted for additional variance

531 in eating and exercise psychopathology, over and above constructs typically associated these

532 variables (e.g., athletes' self-esteem, anxiety, depression, age, BMI, sport type and

533 competitive level). This supports previous research suggesting teammates can play a unique

534 protective / faciliatory role in the development of disordered eating (e.g., Scott et al., 2019).

535 Furthermore, this study also identified relationships between teammate influences and

536 psychological well-being. In line with this, a wide body of literature has demonstrated the

537 link between psychological well-being and eating psychopathology in athletes (Giel et al.,

538 2016; T. A. Petrie, Greenleaf, Reel, \& Carter, 2009a; Shanmugam et al., 2012). Additional

539 research is now required to assess how these constructs interact longitudinally (e.g., via

540 mediation analyses). 
The identification of risk and protective factors, such as teammate influences and

542 indices of psychological wellbeing, are essential in order to facilitate the identification of

543 high-risk groups, appropriately tailor prevention and intervention programmes, and to keep

544 sport policies concerning eating and exercise psychopathology in athletes well informed and

545 relevant (Striegel-Moore \& Bulik, 2007). This study is the first to comprehensively assess the

546 role of multiple potential mechanisms of teammate influence on athletes' eating and exercise

547 attitudes and behaviours. By sampling a large and representative population of athletes and

548 accounting for known covariates of disordered eating and exercise (e.g., BMI, age,

549 psychological wellbeing, sport type and competitive level), this study builds on the

550 limitations of the extant literature. In doing so it has highlighted the sub-populations at

551 increased risk where targeted intervention efforts may be effective - notably, female athletes.

552 There are, however, some limitations. The cross-sectional design did not allow for

553 cause and effect to be determined, meaning that longitudinal and experimental studies are

554 required to determine temporal relationships between teammate influences and disordered

555 eating and exercise attitudes and behaviours. Future research should investigate whether

556 susceptibility to teammate influences changes as a function of sport type and competitive

557 level given research finding the athletes' sport to be a key moderator in the development of

558 disordered eating and exercise attitudes / behaviours (e.g., Chapman \& Woodman, 2016;

559 Rosendahl et al., 2009; Schaal et al., 2011; Voelker et al., 2018). In addition, it is important

560 that influences from the athlete's coach are not overlooked. For example, conflicting coach-

561 athlete relationships and coach pressure have been linked to athletes' disordered eating

562 (Coker-Cranney \& Reel, 2015; Jones, Glintmeyer \& Mckenzie, 2005). Therefore, future

563 research would benefit from assessing both teammate and coach influences in tandem to

564 ascertain their relative strength when predicting disordered eating and exercise. Finally,

565 around half $(51 \%)$ of the athletes in the sample reported competing in individual sports (but 
566

567

568

569

570

571

572

573

574 levels of healthy exercise attitudes and behaviours. In contrast, negative mechanisms of

575 influence had the opposite relationship; modelling of teammates' disordered eating

576 behaviours and perceived pressure from teammates to lose weight / change shape were the

577 best predictors of elevated disordered eating and exercise. These findings are important as

578

579

580

581

582

583

584 Declarations of interest: None

585 Funding: Charlotte L Scott is funded by a PhD studentship awarded by the School of Sport,

586 Exercise and Health Sciences at Loughborough University, UK. 
601

602

603

604

605

606

607

608

609

610

611

612

613

614

615

616

617

618

619

620

621

622

623

624

625

626

627

628

629

630

631

632

633

634

635

636

\section{References}

Anderson, C., \& Petrie, T. A. (2012). Prevalence of Disordered Eating and Pathogenic Weight Control Behaviors Among NCAA Division I Female Collegiate Gymnasts and Swimmers. Research Quarterly for Exercise \& Sport, 83(1), 120-124.

Bauer, K. W., Nelson, M. C., Boutelle, K. N., \& Neumark-Sztainer, D. (2008). Parental influences on adolescents' physical activity and sedentary behaviour: longitudinal findings from Project EAT-II. Internal Journal of Behavioural Nutrition and Physical Activity, 5(1), 12.

Berry, T., \& Howe, L. (2000). Risk factors for disordered eating in female university athletes. Journal of Sport Behavior, 23(3), 207-218.

Bonci, C. M., Bonci, L. J., Granger, L. R., Johnson, C. L., Malina, R. M., Milne, L. W., ... Vanderbunt, E. M. (2008). National Athletic Trainers' Association position statement: preventing, detecting, and managing disordered eating in athletes. Journal of Athletic Training, 43(1), 80-108.

Brannan, M., Petrie, T. A., Greenleaf, C., Reel, J., \& Carter, J. (2009). The relationship between body dissatisfaction and bulimic symptoms in female collegiate athletes. Journal of Clinical Sport Psychology, 3(2), 103-126.

Chan, D. K., Lonsdale, C., \& Fung, H. H. (2012). Influences of coaches, parents, and peers on the motivational patterns of child and adolescent athletes. Scandinavian Journal of Medicine \& Science in Sports, 22(4), 558-568.

Chapman, J., \& Woodman, T. (2016). Disordered eating in male athletes: a meta-analysis. Journal of Sports Sciences, 34(2), 101-109.

Dixey, R. (1996). Healthy Eating in Schools and "Eating Disorders" - Are "Healthy Eating" Messages Part of the Problem or Part of the Solution? Nutrition And Health, 11(1), 4958.

Engel, S. G., Johnson, C., Powers, P. S., Crosby, R. D., Wonderlich, S. A., Wittrock, D. A., \& Mitchell, J. E. (2003). Predictors of disordered eating in a sample of elite Division I college athletes. Eating Behaviors, 4(4), 333-343.

Filaire, E., Rouveix, M., Pannafieux, C., \& Ferrand, C. (2007). Eating attitudes, perfectionism and body-esteem of elite male judoists and cyclists. Journal of Sports Science \& Medicine, 6(1), 50-57.

Flament, M. F., Hill, E. M., Buchholz, A., Henderson, K., Tasca, G. A., \& Goldfield, G. (2012). Internalization of the thin and muscular body ideal and disordered eating in adolescence: The mediation effects of body esteem. Body Image, 9(1), 68-75.

Galli, N., Petrie, T. A., Reel, J. J., Chatterton, J. M., \& Baghurst, T, M. (2014). Assessing the validity of the Weight Pressures in Sport Scale for Male Athletes. Psychology of Men \& Masculinity, 15(2), 170.

Galli, N., Petrie, T., \& Chatterton, J. (2017). Team weigh-ins and self-weighing: Relations to body-related perceptions and disordered eating in collegiate male athletes. Psychology of Sport and Exercise, 29(3), 51-55.

Garner, D. M. (1991). Eating disorder inventory-2. Professional Manual. Odessa, FL: Psychological Assessment Resources.

Giel, K. E., Hermann-Werner, A., Mayer, J., Diehl, K., Schneider, S., Thiel, A., ... Group, G. study. (2016). Eating disorder pathology in elite adolescent athletes. International Journal of Eating Disorders, 49(6), 553-562.

Goodwin, H., Haycraft, E., Willis, A, M., \& Meyer, C. (2011). Compulsive exercise: The role of personality, psychological moribity, and disordered eating. International Journal of Eating Disorders, 44(7), 655-660.

Greenleaf, C., Petrie, T. A., Carter, J., \& Reel, J. J. (2009). Female collegiate athletes: Prevalence of eating disorders and disordered eating behaviours. Journal of American 
College Health, 57(5), 489-496.

Greenleaf, C., Petrie, T. A., Reel, J., \& Carter, J. (2010). Psychosocial risk factors of bulimic symptomatology among female athletes. Journal of Clinical Sport Psychology, 4(3), 177-190.

Halfdanardottir, B. F. (2016). Anxiety and Depression Symptoms in Athlete and Their Attitudes Towards These Problems. Doctoral Dissertation. University of Iceland http://hdl.handle.net/1946/23642, Accessed date: 10 January 2019.

Hausenblas, H., \& Carron, A. (2000). Group influences on eating and dieting behaviors in male and female varsity athletes. Journal of Sport Behavior, 23(1), 33.

Hausenblas, H., \& McNally, K. (2004). Eating disorder prevalence and symptoms for track and field athletes and nonathletes. Journal of Applied Sport Psychology, 16(3), 274-286.

Helsen, M., Vollebergh, W., \& Meeus, W. (2000). Social support from parents and friends and emotional problems in adolescence. Journal of Youth and Adolescence, 29(3), 319335.

Holm-Denoma, J. M., Scaringi, V., Gordon, K, H., Van Orden, K, A., \& Joiner Jr, T, E. (2009). Eating disorder symptoms among undergraduate varisty athletes, club athletes, independent exercises, and nonexercisers. International Journal of Eating Disorders, $42(1), 47-53$.

Homan, K. (2010). Athletic-ideal and thin-ideal internalization as prospective predictors of body dissatisfaction, dieting, and compulsive exercise. Body Image, 7(3), 240-245.

Jowett, S. (2009). Validating coach-athlete relationship measures with the nomological network. Measurement in Physical Education and Exercise Science, 13(1), 34-51.

Kroshus, E., Goldman, R. E., Kubzansky, L. D., \& Austin, S. B. (2014). Team-level approaches to addressing disordered eating: A qualitative study of two female collegiate cross country running teams. Eating Disorders, 22(2), 136-151.

Kroshus, E., Kubzansky, L., Goldman, R., \& Austin, S. B. (2015). Anti-dieting advice from teammates: a pilot study of the experience of female collegiate cross country runners. Eating Disorders, 23(1), 31-44.

Krueger, J., \& Clement, R. (1994). The truly false consensus effect: An ineradicable and egocentric bias in social perception. Journal of Personality and Social Psychology, 67(4), 596-610.

Larson, N. I., Neumark-Sztainer, D., Harnack, L., Wall, M., Story, M., \& Eisenberg, M. E. (2008). Fruit and vegetable intake correlates during the transition to young adulthood. American Journal of Preventative Medicine, 35(1), 33-37.

Lenne, R., Panos, M., Auster-Gussman, L., Scherschel, H., Zhou, L., \& Mann, T. (2017). Behavioural Compensation Before and After Eating at the Minnesota State Fair. Appetite, 118, 113-119.

Madigan, D., Stoeber, J., \& Passfield, L. (2017). Athletes' perfectionism and reasons for training: Perfectionistic concerns predict training for weight control. Personality and Individual Differences, 115, 133-136.

Martinsen, M., Bratland-Sanda, S., Eriksson, A., \& Sundgot-Borgen, J. (2010). Dieting to win or be thin? A study of dieting and disordered eating among adolescent elite athletes and non-athlete controls. British Journal of Sports Medicine, 44(1), 70-76.

McNamara, J., \& McCabe, M. P. (2012). Striving for success or addiction? Exercise dependence among elite Australian athletes. Journal of Sport Sciences, 30(8), 755-766.

McVey, G. L., Lieberman, M., Voorberg, N., Wardrope, D., \& Blackmore, E. (2003). School-based peer support groups: A new approach to the prevention of disordered eating. Eating Disorders, 11(3), 169-185.

Muscat, A. C., \& Long, B. C. (2008). Critical comments about body shape and weight: Disordered eating of female athletes and sport participants. Journal of Applied Sport 
Psychology, 20(1), 1-24.

Neumark-Sztainer, D., Story, M., Hannan, P., Perry, C., \& Irving, L. (2002). Weight-related concerns and behahaviours among overweight and nonoverweight adolescents: implications for preventing weight-related disorders. Archives of Pediatrics \& Adolescent Medicine, 156(2), 171-178.

Nichols, J. F., Rauh, M. J., Barrack, M. T., Barkai, H.-S., \& Pernick, Y. (2007). Disordered Eating and Menstrual Irregularity in High School Athletes in Lean-Build and NonleanBuild Sports. International Journal of Sport Nutrition \& Exercise Metabolism, 17(4), 364-377.

Petrie, T. A., \& Greenleaf, C. (2007). Eating Disorders in Sport. In G. Tenenbaum \& R. C. Ecklunc (Eds.), Handbook of Sport Psychology (pp. 352-378). Hoboken, NJ: John Wiley.

Petrie, T. A., \& Greenleaf, C. (2012). Eating Disorders in Sport. In S. M. Murphy (Ed.), Oxford library of psychology. The Oxford Handbook of Sport and Performance Psychology (pp. 635-659). New York, NY, US: Oxford University Press.

Petrie, T. A., Greenleaf, C., Carter, J. E., \& Reel, J. J. (2007). Psychosocial correlates of disordered eating among male collegiate athletes. Journal of Clinical Sport Psychology, $1(4), 340-357$.

Petrie, T. A., Greenleaf, C., Reel, J., \& Carter, J. (2009a). Personality and psychological factors as predictors of disordered eating among female collegiate athletes. Eating Disorders, 17(4), 302-321.

Petrie, T. A., Greenleaf, C., Reel, J. J., \& Carter, J. E. (2009b). An Examination of Psychosocial Correlates of Eating Disorders Among Female Collegiate Athletes. Research Quarterly for Exercise \& Sport, 80(3), 621-632.

Petrie, T., Greenleaf, C., Reel, J., \& Carter, J. (2008). Prevalence of eating disorders and disordered eating behaviours among male collegiate athletes. Psychology of Men \& Masculinity, 9(4), 267-277.

Plateau, C. R., Shanmugam, V., Duckham, R., Goodwin, H., Jowett, S., Brooke-Wavell, K., ... Meyer, M. (2014). Use of the Compulsive Exercise Test with athletes: norms and links with eating psychopathology. Journal of Applied Sport Psychology, 26(3), 287301.

Plessow, F., Singhal, V., Toth, A. T., Micali, N., Eddy, K. T., \& Misra, M. (2018). Estrogen Administration Improves the Trajectory of Eating Disorder Pathology in Oligoamenorrheic Athletes: A Randomized Trial. Psychoneuroendocrinology, 102(4) 273280.

Reel, J., Petrie, T. A., Soohoo, S., \& Anderson, C. M. (2013). Weight pressures in sport: Examining the factor structure and incremental validity of the weight pressures in sportFemales. Eating Behaviors, 14(2), 137-144.

Ringham, R., Klump, K., Kaye, W., Stone, D., Libman, S., Stowe, S., \& Marcus, M. (2006). Eating disorder symptomatology among ballet dancers. International Journal of Eating Disorders, 39(6), 503-508.

Rosenberg, M. (1965). Rosenberg self-esteem scale (RSE). Acceptance and Commitment Therapy. Measures Package, 61, 61-62.

Rosendahl, J., Bormann, B., Aschenbrenner, F., \& Strauss, B. (2009). Dieting and disordered eating in German high school athletes and non-athletes. Scandinavian Journal of Medicine \& Science in Sports, 19(5), 731-739.

Sallis, James, F., Grossman, Robin, M., Pinski, Robin, R., Patterson, Thomas, L., \& Nader, Philip, R. (1987). The development of scales to measure social support for diet and exercise behaviours. Preventive Medicine, 16(6), 825-836.

Schaal, K., Tafflet, M., Nassif, H., Thibault, V., Pichard, C., Alcotte, M., ... Toussaint, J. 
(2011). Psychological balance in high level athletes: gender-based differences and sportspecific patterns. Plos One, 6(5), e19007.

Scoffier, S., Maïano, C., \& d'Arripe-Longueville, F. (2010). The effects of social relationships and acceptance on disturbed eating attitudes in elite adolescent female athletes: The mediating role of physical self-perceptions. International Journal of Eating Disorders, 43(1), 65-71.

Scott, C., Haycraft, E., \& Plateau, C. R. (2019). Teammate influences on the eating attitudes and behaviours of athletes: A systematic review. Psychology of Sport and Exercise, 43(7), 183-194.

Segura-Garcia, C., Papaianni, M. C., Caglioti, F., Procopio, L., Nistico, C. G., Bombardiere, L., .. Capranica, L. (2012). Orthorexia nervosa: a frequent eating disordered behaviour in athletes. Eating and Weight Disorders-Studies on Anorexia, Bulimia and Obesity, 17(4), e226-e233.

Shanmugam, V. (2011). The prevalence and psychosocial correlates of British athletes' eating psychopathology. Doctoral Dissertation. Loughborough University https://dspace.lboro.ac.uk/2134/9213, Accessed date: 15 February 2019.

Shanmugam, V., Jowett, S., \& Meyer, C. (2012). Eating psychopathology amongst athletes: Links to current attachement styles. Eating Behaviors, 13(1), 5-12.

Shanmugam, V., Jowett, S., \& Meyer, C. (2013). Eating psychopathology amongst athletes: The importance of relationships with parents, coaches and teammates. International Journal of Sport and Exercise Psychology, 11(1), 24-38.

Shanmugam, V., Jowett, S., \& Meyer, C. (2014). Interpersonal difficulties as a risk factor for athletes' eating psychopathology. Scandinavian Journal of Medicine \& Science in Sports, 24(2), 469-476.

Smith, A. L., Ullrich-French, S., Walker, E., \& Hurley, K. S. (2006). Peer relationship profiles and motivation in youth sport. Journal of Sport \& Exercise Psychology, 28(3), 362-382.

Stern, F. (2014). The hospital anxiety and depression scale. Occupational Medicine, 64(5), 393-394.

Stice, E. (1998). Modeling of eating pathology and social reinforcement of the thin-ideal predict onset of bulimic symptoms. Behaviour Research and Therapy, 36(10), 931-944.

Stice, E., \& Bearman, S. K. (2001). Body-image and eating disturbances prospectively predict increases in depressive symptoms in adolescent girls: a growth curve analysis. Developmental Psychology, 37(5), 597-607.

Striegel-Moore, R., \& Bulik, C. (2007). Risk factors for eating disorders. American Psychologist, 62(3), 181-198.

Thompson, J. K., Shroff, H., Herbozo, S., Cafri, G., Rodriguez, J., \& Rodriguez, M. (2006). Relations among multiple peer influences, body dissatisfaction, eating disturbance, and self-esteem: A comparison of average weight, at risk of overweight, and overweight adolescent girls. Journal of Pediatric Psychology, 32(1), 24-29.

Thompson, R. A., \& Sherman, R. T. (2011). Eating disorders in sport. New York: Routledge.

Torstveit, M. K., Rosenvinge, J. H., \& Sundgot-Borgen, J. (2008). Prevalence of eating disorders and the predictive power of risk models in female elite athletes: a controlled study. Scandinavian Journal of Medicine \& Science in Sports, 18(1), 108-118.

Voelker, D. K., Petrie, T. A., Reel, J. J., \& Gould, D. (2018). Frequency and Psychosocial Correlates of Eating Disorder Symptomatology in Male Figure Skaters. Journal of Applied Sport Psychology, 30(1), 119-126.

Walker, S. N., Pullen, C. H., Hertzog, M., Boeckner, L., \& Hageman, P. (2006). Determinants of older rural women's activity and eating. Western Journal of Nursing Research, 28(4), 449-468. 
Weber, S., Puta, C., Lesinski, M., Gabriel, B., Steidten, T., Bar, K., ... Gabriel, H. (2018).

Symptoms of anxiety and depression in young athletes using the Hospital Anxiety and Depression Scale. Frontiers in Physiology, 9(182), 1-12. 